\title{
El subdesarrollo y la crisis capitalista del último tercio del siglo $\mathrm{XX}^{1}$
}

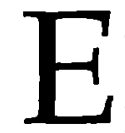

ste texto constituye el tercer y último de la serie en la que hemos venido analizando el fenómeno del subdesarrollo desde la disci plina de la economía. En los anteriores planteamos nuestro enfoque epistemológico y nuestra visión teórica al respecto. En consonancia con lo expuesto en ellos en cuanto a la dimensión histórica del enfoque, pensamos que esa visión ha de ser complementada con la contextualización histórica del período actual. Así, en este artículo, nos vamos a ocupar del subdesarrollo en el contexto de la crisis que se inicia $-\mathrm{o}$, por decirlo con más precisión, estalla, puesto que su inicio es anterior, aunque la crisis como tal permaneciera latente- en el tránsito de los 60 a los 70, y que enmarca la situación actual.

Conviene hacer una aclaración antes de proseguir. No se trata de analizar en profundidad la crisis, ni menos aún de llevar a cabo un estudio de la evolución de la economía mundial durante el siglo XX. Se trata, únicamente, de comprender la evolución capitalista mundial reciente, caracterizada por la crisis, en cuanto a su significado, alcance e implicaciones. Comprensión necesaria para el análisis del papel desempeñado por dicha situación de crisis en los fenómenos actuales.

Para ello, estructuraremos el artículo de la siguiente manera. En orden a poder entender el significado de la crisis - y su impacto en las FSCS-, comenzaremos esbozando un muy breve y sintético repaso a la evolución de la economía mundial durante el siglo XX — período conceptualizado como fase imperialista-, particularmente desde el año 1945. Seguidamente, abordaremos el estudio de la crisis desde una perspectiva global que primará los aspectos interpretativos sobre los meramente descriptivos. De ahí trataremos de obtener una aproximación a la esencia, alcance y significado de la crisis. A partir de ello, nos ocuparemos de la evolución de las FSCS en todo este período, es decir, tanto en los años de expansión inmediatamente posteriores a la Segunda Guerra Mundial como en los de la crisis, valorando el rol asignado a estos países 
en el modelo de acumulación posbélico y el impacto e implicaciones que les supone la crisis. Este último apartado se referirá de manera más específica a los países latinoamericanos. Finalmente, sintetizaremos en una sucinta recopilación los elementos reseñados más relevantes de la evolución de la economía mundial, en su función como al menos una de las variables claves para los estudios de caso $^{3}$.

\section{La economía mundial después de 1945: imperialismo y modelo de acumulación posbélico}

Todo el período que se extiende a lo largo del siglo XX conforma la fase imperialista del desarrollo capitalista. Su principal característica es la consolidación de una sola economía mundial a la que todos los países están, de una u otra manera, vinculados. Es una fase en la que se enfatiza la concentración y centralización del capital, agudizándose la tendencia al monopolio, con -y esto es muy importante- preponderancia del capital financiero - resultado de la fusión del bancario con el industrial-. El predominio de la exportación de capitales sobre la de productos lleva a una relativa autonomía de los circuitos financieros respecto de los de producción de mercancías. El desfase temporal entre producción y venta, debido a la utilización masiva del crédito, implica la presencia, creciente, de circuitos de capital ficticio en los que el dinero produce dinero sin pasar por el ámbito de la producción. Todo esto incrementa el componente especulativo en el desempeño de la economía mundial. Además, persiste la tendencia al desarrollo desigual de las distintas formaciones sociales lo que lleva a la mayoría de las subdesarrolladas -objeto de reparto como "áreas de influencia" de las desarrolladas respectivas- a profundizar su situación de subdesarrollo y dependencia.

Elementos todos estos que aparecen recogidos por Lenin $(1974 ; 99)$, cuando señala que "conviene dar una definición del imperialismo que contenga los cinco rasgos fundamentales siguientes: 1) la concentración de la producción y del capital llegada hasta un grado tan elevado de desarrollo, que ha creado los monopolios, los cuales desempeñan un papel decisivo en la vida económica; 2) la fusión del capital bancario con el industrial y la creación, sobre la base de este 'capital financiero', de la oligarquía financiera; 3) la exportación de capitales, a diferencia de la exportación de mercancias, adquiere una importancia particularmente grande; 4) la formación de asociaciones internacionales monopolistas de capitalistas, las cuales se reparten el mundo, y 5) la terminación del reparto territorial del mundo entre las potencias capitalistas más importantes. El capitalismo es la fase de desarrollo en que ha tomado cuerpo la dominación de los monopolios y del capital financiero, ha adquirido señalada importancia la exportación de capitales, ha empezado el reparto del mundo por los trusts internacionales y ha terminado el reparto de toda la tierra entre los países capitalistas más importantes" 4. 
En este contexto, el modelo de acumulación que surge a partir de la Segunda Guerra Mundial supondrá un intento de reversión de la tendencia crítica que atraviesa la economía mundial. Dicha situación subyace desde el paso de la hegemonía inglesa a la estadounidense que se inicia a fines del siglo XIX, consolidándose en la primera mitad del siglo actual. Este período aparece jalonado, especialmente, por tres hechos: la Primera Guerra Mundial, la llamada crisis del 29 y la Segunda Guerra Mundial. Hechos que no son sino manifestaciones de una crisis capitalista más amplia que no encuentra vía de solución sostenida, excediendo lo que guarda relación con la dimensión cíclica del modo de producción capitalista5.

Finalmente, casi coincidiendo con el final de la Segunda Guerra Mundial, en la Conferencia de Bretton Woods (1944) se sientan las bases institucionales de lo que será, para las décadas siguientes, la concreción específica - histórica - de la lógica de acumulación capitalista que denominamos modelo de acumulación posbélico. Si bien su consolidación consigue mostrar tasas importantes de crecimiento y otros indicadores de recuperación, se asienta sobre unas bases tremendamente inestables cuya ruptura se encuentra en el origen del estallido de la crisis de finales de los sesenta/principios de los setenta.

En el marco de esta fase capitalista, en los años 1944 y 1945 se dan una serie de circunstancias históricas - resultado, básicamente, del conflicto bélico y de los acuerdos y conferencias internacionales acaecidos (Teherán, Yalta, Potsdam: donde se plasma el marco de colaboración con los regímenes estalinistas encabezados por la propia Unión Soviética)que colocan a Estados Unidos en una situación de dominio de la economía mundial muy superior a aquella de la que disponía después de la Primera Guerra Mundial. Es justamente en la Conferencia de Bretton Woods donde se consagra la hegemonía de Estados Unidos.

Esta hegemonía se basará, en gran medida, en el sistema monetario que se impone en esta Conferencia. Consiste en la consideración del dólar como moneda de cambio internacional, ligada directamente al oro del que es perfectamente convertible, de manera que el resto de monedas se intercambian a partir de la existencia de tasas fijas de paridad respecto al dólar (propuesta también apoyada por la propia Unión Soviética). Esto va a posibilitar y reforzar la hegemonía de Estados Unidos y le va a permitir liderar un patrón de crecimiento basado en gran medida en elementos monetarios y financieros - entre los cuales la inflación desempeña un papel crucial como mecanismo de transferencia de recursos-, en consonancia con la fase imperialista del desarrollo capitalista mundial, caracterizada, como decíamos, por el predominio del capital finan- 
ciero. Otro elemento de gran importancia lo constituye la economía de armamento que aparece como uno de los factores más relevantes en la explicación de los conflictos bélicos posteriores: Guerra de Corea, Guerra de Vietnam y otros. El armamentismo guarda relación tanto con el mantenimiento de la condición de potencia hegemónica de Estados Unidos como, y especialmente en relación al tema objeto de estudio, con la propia función económica del sector.

En el contexto del predominio del capital financiero, que aparece vehiculizado a través de la hegemonía estadounidense, se consolida un nuevo modelo de acumulación6. Se basa en una renovación de la base tecnológica y energética, en la modificación de algunos aspectos de la organización del trabajo, en una mayor intervención del Estado - tanto cuantitativa como cualitativa- que asegure la reproducción del sistema, en transformaciones en el sistema de transporte y comunicaciones así como en las redes de distribución y comercialización, etcétera. Pero donde su lógica alcanza pleno funcionamiento es en el terreno de las relaciones internacionales, de la economía mundial como un todo. Así, se profundiza la división internacional del trabajo ya preexistente, a través de la internacionalización del capital productivo, de la actuación de las empresas transnacionales oligopólicas, del predominio de los circuitos financieros sobre los directamente productivos, y del rol creciente jugado por organismos internacionales como el Fondo Monetario Internacional o el Banco Mundial entre otros?.

\section{La crisis: más allá de la coyuntura y del ciclo}

El estallido de la crisis en el tránsito de la década de los 60 a la de los 70 pone de relieve la plena vigencia de toda una serie de problemas centrales apartados - en realidad, hechos desaparecer- de las discusiones académicas tras la Segunda Guerra Mundial. Las elevadas tasas de crecimiento, la consecución de niveles de ocupación próximos a los de pleno empleo, el crecimiento del comercio mundial por encima de la producción, la existencia de tasas relativamente reducidas de inflación, entre otros indicadores, desplazaban del mundo académico los temas vinculados a la reproducción del sistema en el tiempo, a la permanencia de una gran parte de la población mundial al margen de los frutos del crecimiento e incluso a las bases sobre las que se asentaba el logro de esos indicadores. La no consideración de estas cuestiones se fundamentaba en la pretendida superación de las contradicciones capitalistas con la aplicación, en mayor o menor medida, de políticas keynesianas en los países desarrollados. Políticas que condujeron a distintas conformaciones del "Estado del Bienestar" según los países y cuya aplicación fue debida, en parte a la necesidad del capital de aumentar la intervención del Estado 
como demandante, para asegurar la reproducción y en parte a la organización política y sindical de la clase trabajadora.

Con toda crudeza, pronto se pudo observar que la crisis iba mucho más allá de lo que podían explicar interpretaciones basadas en su supuesto carácter meramente coyuntural o cíclico. Con independencia de que, aún hoy día, sigan existiendo visiones de la crisis centradas únicamente en elementos parciales, como el alza de los precios del petróleo del año 1973 o la quiebra de la convertibilidad dólar-oro en 1971. La interrelación de estos elementos junto a algunos otros, ponía claramente de manifiesto el verdadero carácter del pretendidamente "exitoso" modelo de acumulación posbélico. La quiebra de éste ponía de relieve el grado de crisis estructural del propio sistema capitalista en cuanto a su reproducción en el tiempo, expresando la agudización de sus contradicciones -ciertamente no resueltas - : la paradoja desarrollo/destrucción de fuerzas productivas, el problema de la realización, las condiciones de valorización del capital, etcétera, expresiones a su vez de la contradicción esencial sintetizada en la oposición capital-trabajo. Vamos a profundizar más en estas cuestiones.

El primer elemento importante de ser tenido en cuenta es el tipo de lógica económica en que hunde sus raíces la crisis. Más específicamente, la concreción que toma la lógica de acumulación capitalista en las dos décadas siguientes a la Segunda Guerra Mundial. Expresado de otro modo, tenemos, por un lado, el proceso abstracto o teórico de crisis capitalista, y por el otro, la concreción de dicho proceso abstracto en una determinada realidad histórica de desarrollo capitalista, lo que explica la escala y el alcance con los que efectivamente se produce.

La crisis surge, en esencia, de la caída de la tasa media de ganancia (como consecuencia de su relación directa con la plusvalía, que disminuye $o$, a lo sumo, se mantiene, e inversa con la relación capital-trabajo, que aumenta). Tasa de ganancia cuya maximización es el objetivo que guía la actuación del capital8. De ahí que su caída genere toda una serie de acciones que confluyen en la recesión y en el estancamiento. Por lo cual, la tarea del capital se centra en intentar restaurar las condiciones de acumulación, de la transformación de ganancia en capital "productivo" para incrementar la ganancia, es decir, de valorización del capital. Se hace necesario entonces el aumento de la tasa de explotación del trabajo mediante la reducción absoluta o relativa de los salarios. Otros mecanismos para intentar recuperar la tasa de ganancia tienen que ver con la expansión mundial capitalista. Son la exportación de capitales, bajo la forma de inversión directa -deslocalización-, para aprovechar los costes de trabajo inferiores, o de inversión en cartera, tanto para la ganancia especula- 
tiva como para el control de la plusvalía; la exportación de mercancías para ensanchar el mercado y la importación de mercancías producidas a precios más bajos. Esto es, mecanismos que permitan y aseguren el incremento de la transferencia de recursos recibida del exterior - a través de un incremento de la tasa de explotación, o más concretamente de la de sobreexplotación-. Pero todo ello no se produce de igual manera en los distintos períodos históricos, sino que presenta diversas modalidades. Lo que nos interesa aquí es la modalidad de concreción específica que toma la crisis que nos ocupa. $Y$ ésta se caracteriza por una serie de rasgos entre los cuales se cuenta la agudización de la tendencia al control oligopólico del mercado mundial que aparece crecientemente dominado por unos pocos grupos industriales y financieros, en los que estos últimos tienden a prevalecer.

Todo el modelo de acumulación posbélico como tal empieza a dar las primeras señales de agotamiento, de imposibilidad de mantenimiento en el tiempo, en la segunda mitad de la década de los sesenta. Los índices de crecimiento empiezan a remitir y las relaciones internacionales están gravemente amenazadas por la persistencia de un sistema monetario que genera una alta inestabilidad. Así, la declaración del presidente estadounidense Nixon -año 1971- de no convertibilidad dólar-oro supone la quiebra de uno de los pilares de este modelo. La crisis ya es una realidad evidente. Posteriormente, el alza de los precios del petróleo — 1973 — asesta otro duro golpe por el determinante papel que juega este recurso en el patrón energético-tecnológico asociado a la base productiva del modelo.

Aparecen la recesión, el estancamiento productivo -y sobre todo industrial-, la inflación, el desempleo, la caída de la inversión, las distorsiones en el intercambio comercial - déficit estadounidense creciente lo que va a generar un elevado monto de divisas en Europa, los "eurodólares", que unidas a las derivadas del incremento del precio del petróleo, los "petrodólares" están en la base del auge de los mercados financieros internacionales en la década de los setenta-, desajustes en el sistema monetario, déficits públicos. Pero estos fenómenos (incluidos los comentados de la ruptura de convertibilidad dólar-oro y el alza de los precios del petróleo) no son la crisis, sino su expresión. Son manifestaciones externas de un proceso que no es claramente delimitable en el tiempo dado que, en todo caso, su carácter va más allá de lo meramente coyuntural o parcial. Efectivamente, la crisis no es la crisis financiera ni la crisis energética. La crisis es la ruptura de todo un modelo de acumulación: el que parte del punto de inflexión de la Segunda Guerra Mundial.

Pero el alcance de la crisis es aún mayor porque la quiebra del modelo de acumulación posbélico es, justamente, la quiebra del intento de 
revertir la situación de crisis crónica subyacente a lo largo de todo el siglo XX. Así, esta crisis expresa la caída de una tasa de ganancia basada, crecientemente, en la esfera de la circulación: en el predominio del capital financiero, en la preponderancia de la exportación de capitales sobre la de productos, en la relativa autonomía de los circuitos financieros respecto a los de producción de mercancías, en la renta de monopolio, en las relaciones de dominación entre Estados y en el componente especulativo por sobre el componente productivo. Crisis que no es sino la crisis del imperialismo, entendido como la fase suprema del capitalismo.

Como certeramente señala Gill $(1983 ; 8)$, "si el desarrollo de la economía mundial constituye un progreso histórico incontestable para la humanidad, este desarrollo (bajo el régimen de la propiedad privada de los medios de producción y sometido a la ley de la ganancia) esta bloqueado en su verdadera finalidad por la acentuación de las tensiones nacionales e internacionales, por la persistencia de la crisis crónica, económica, política y social del sistema. Este es el hecho de todo el siglo XX, periodo del imperialismo, período de las guerras y de las revoluciones. Si el periodo de unos 25 años que ha seguido a la Segunda Guerra mundial ha podido dejar creer que el capitalismo mundial habia encontrado los medios de darse una nueva estabilidad, de desembarazarse de las crisis y de asegurarse un crecimiento sostenido, el resurgimiento, desde el fin de los años sesenta, de los problemas que se pretendian tener definitivamente superados, su agravamiento total en el curso de los años setenta y la convicción creciente de su irresolubilidad que se desprendía al principio de los años 80, demostraron, contra toda pretensión contraria, la persistencia de esta crisis crónica de todo el régimen entero. Sólo las condiciones excepcionales de la posguerra (destrucción de masas enormes de fuerzas productivas, sobreexplotación de la fuerza de trabajo, pillaje de los países subdesarrollados...) y los medios artificiales (expansión del crédito y del endeudamiento, relanzamiento de los gastos militares...) han permitido dejar creer que era cosa de paso".

Este es el contexto mundial del que deriva directamente el período actual.

\section{Imperialismo, crisis, transnacionalización y subdesarrollo}

Después de haber analizado, de forma muy sintética, las principales tendencias en la economía mundial desde la Segunda Guerra Mundial hasta la crisis, en este apartado abordaremos el estudio de la evolución económica de los países subdesarrollados en este período.

En el primer artículo de esta serie, mencionamos la complejidad de hacer la abstracción suficiente para hablar de formación social capitalista subdesarrollada "típica", dada la enorme heterogeneidad existente entre los distintos países. Si ello es así en un plano no definido temporalmente, 
cuando tratamos de un período histórico concreto y más delimitado, dicha complejidad se torna mayor. Por ello, en este apartado nos referiremos, fundamentalmente, al caso de los países del área latinoamericana9.

Ya hemos visto la manera en que el origen del subdesarrollo aparecía ligado a la expansión del modo de producción capitalista, lo que determinaba el tipo de inserción de cada formación social en la división internacional del trabajo. De este modo, a través de las distintas fases de desarrollo capitalista, América Latina consolida una posición típicamente primario-exportadora en la mencionada división internacional del trabajo. Como expusimos previamente, esto implica una dependencia exterior y una vulnerabilidad asociada a ella de tremenda magnitud, que, unidas a distorsiones en la estructura interna, están en la raíz de la lógica de reproducción del subdesarrollo.

Durante la fase que hemos conceptualizado como imperialista, esta lógica, lejos de alterarse, tiende a profundizarse en el tiempo. Así, tanto la Primera Guerra Mundial como la "crisis del 29" tienen efectos catastróficos para la región. Nuevamente, la cuestión, sin duda central, consistente en depender de la demanda exterior como fundamental elemento de demanda de los principales sectores productivos - por la escasa articulación del mercado interno- lleva a que las fluctuaciones en los países que sostienen dicha demanda les afecten en mucha mayor magnitud. Es la perversa vinculación entre la estructura productiva, la inserción exterior y la modalidad de distribución del ingreso, verdadero armazón de la esencia del subdesarrollo.

Constatando todo esto, por vez primera empiezan a surgir desde estos países análisis teóricos sobre el fenómeno. Análisis que tendrán una enorme influencia en las políticas aplicadas. El más importante es el que realiza la Comisión Económica para América Latina - CEPAL - de Naciones Unidas en los años inmediatamente posteriores a la Segunda Guerra mundial. Su principal exponente es Prebisch. En su análisis, este autor plantea una crítica a la teoría clásica del comercio internacional. Exponiéndolo de forma muy simplificada, esta formulación clásica sostiene que el comercio entre dos países es ventajoso para ambos, independientemente del tipo de producto con el que participe cada uno de ellos. Prebisch sugiere que esta idea encierra una posición claramente funcional a los intereses de los países desarrollados - a los que denomina genéricamente "centro", frente a los países subdesarrollados o "periferia"por cuanto que el tipo de producto exportado y la forma en que se produce son factores decisivos para examinar cuánto de favorable $\longrightarrow$ noes la relación comercial de un país con el exterior.

Con base en esto y para explicar la situación de subdesarrollo en los 
países latinoamericanos, Prebisch acuña su famosa teoría del deterioro o caída tendencial de la relación de precios de intercambio de estos países, consecuencia de su inserción primario-exportadora. Como su propia denominación indica, esta teoría sostiene que la causa del subdesarrollo radica en este tipo de inserción, de manera que la brecha de los países subdesarrollados con los desarrollados no tenderá a reducirse sino a ampliarse en el tiempo, por la pérdida de poder adquisitivo de aquellos derivada de la tendencia al deterioro de los precios de sus productos de exportación respecto de los precios de sus productos de importación. Lo que se pone en entredicho es, por tanto, la opción de "crecimiento hacia afuera". Frente a esto, se considera la necesidad de la industrialización como instrumento para el desarrollo. Más concretamente, una modalidad específica de industrialización atendiendo a la imposibilidad de llevar a cabo este proceso industrializador con el tipo de inserción existente. Dicha modalidad será la industrialización por sustitución de importaciones, opción de "crecimiento hacia adentro", para la cual resulta imprescindible un activo papel del Estado, especialmente en la primera fase, protegiendo la "industria naciente".

Políticas inspiradas en esta opción se aplican en numerosos países latinoamericanos, fundamentalmente durante las décadas de los 50 y de los 60 - es decir, durante el período de expansión de las economías desarrolladas10- No obstante, su alcance e intensidad así como la periodización varían mucho entre países, en algunos de los cuales ya había activas políticas estatales industrializadoras desde antes incluso de los años treinta.

A pesar de ciertas cotas de crecimiento y de aumento de la participación del sector industrial, en la segunda mitad de la década de los sesenta ya se empieza a percibir el fracaso de este modelo industrializador. Este fracaso se explica por varios factores. De un lado por los desequilibrios financieros y comerciales externos, en una medida considerable, por la necesidad de importación de insumos requeridos para la industrialización y por la exigua consolidación de los intentos de diversificación de la estructura de exportaciones. De otro lado por los desequilibrios internos, expresados en la desarticulación de los distintos sectores y procesos productivos -desarticulación concretada, especialmente, en la no integración vertical- y en las elevadas tasas de inflación. Finalmente y de manera especial, por el mantenimiento de una estructura de distribución del ingreso tremendamente concentrada que impide la conformación de un mercado interno importante que pueda constituirse en un incentivo de demanda para la producción industrial y la articulación intersectorial-. Elemento éste que permanece estrechamente vinculado a la integración de estos países en la economía mundial, en cuan- 
to a la apropiación y utilización del excedente en ellas generado.

Si bien es cierto que la inexistencia de una estructura industrial sólida se encontraba en la explicación del subdesarrollo, no se puede decir, sin embargo, que fuera la causa última. De manera que, intentar una transformación de la estructura productiva -por más que se contara con todo el aparato del Estado y con una buena coyuntura mundial- sin afectar la propia esencia de la lógica capitalista de la división internacional del trabajo operando a escala mundial y sin abordar otras cuestiones internas entre la que destaca poderosamente la estructura distributiva tremendamente concentrada y excluyente, estaba, de antemano, condenada al fracaso11.

Con los primeros efectos de la crisis mundial, las contradicciones de este modelo industrializador se expresan con mayor intensidad. Añadidamente, ya en la década de los setenta, el auge de los mercados financieros derivado del exceso de liquidez -"eurodólares" por el déficit comercial de Estados Unidos con Europa y "petrodólares" por el superávit de los países exportadores de petróleo procedente del alza en los precios- permite vivir una situación irreal en la que, como el crédito es tremendamente barato - se llegó a tasas de interés real negativas-, se recurre a él sin responsabilidad y medida alguna12. Paulatinamente se da una despreocupación mayor respecto de las necesidades de la esfera productiva y, especialmente, del sector industrial. La idea del impulso al desarrollo industrializador endógeno está casi abandonada, no obstante lo cual, hay que reseñar que la situación varía mucho entre los distintos países.

El fin de este "sueño" llega en los primeros años de la década de los ochenta cuando las tasas de interés aumentan de forma vertiginosa, los precios de los productos de exportación de estos países caen aceleradamente y los capitales dejan de afluir, incrementándose la presión de los bancos deudores 13 . El despilfarro de los créditos recibidos -y aquí la situación también varía mucho entre los distintos países: su fuga al exterior, su uso suntuario, armamentista, etcétera- dificultan aún más la situación.

La explosión de la llamada crisis de la deuda tiene su episodio más significativo en el año 1982, con la declaración mexicana de imposibilidad de atender el pago de la deuda. A partir de ese momento, declaraciones similares se suceden. Seguidamente, comienza la etapa de las negociaciones con el Fondo Monetario Internacional y los bancos acreedores. Por la trascendencia que tiene este punto, nos detendremos algo más en él. 
La "ayuda" del FMI para la renegociación de la deuda "está subordinada a la adopción por los países deudores de medidas correctivas"14. Es, por tanto, una ayuda condicional. "La condicionalidad se refiere a la obligación, impuesta por el Fondo a los países miembros que desean recurrir a sus recursos, de adoptar las políticas de ajuste económico (...). El vínculo entre el financiamiento y el ajuste está en el centro de la condicionalidad"15.

Todas estas políticas impuestas por el FMI se inspiran en los presupuestos teóricos de la escuela neoliberal16. Para esta escuela, el fundamento principal de la política económica radica en la consideración de que toda intervención estatal altera el libre juego de las fuerzas de mercado, único método para alcanzar el equilibrio y la eficiencia - retomando la idea de la "mano invisible" de Smith-. Por tanto, plantea la abolición de todos los controles -origen de las distorsiones-mediante la liberalización indiscriminada, tanto interna como externa.

En consonancia con ello, el diagnóstico y las recomendaciones del Fondo son siempre las mismas 17. Para el FMI, la crisis de los países subdesarrollados toma tres expresiones: fuerte inflación, elevado déficit de la balanza de pagos y escasez de ahorro. Su razonamiento es el siguiente: el exceso de gasto público (demasiados funcionarios, control de precios de productos básicos mediante subvenciones, mantenimiento de empresas no rentables...) produce varios efectos negativos. En primer lugar, un exceso de consumo que genera, también, una tendencia al crecimiento de importaciones y, a su vez, un incremento del déficit comercial. En segundo lugar, una fuerte inflación - por la creación monetaria- que lleva a reducir la competitividad y contraer las exportaciones. En tercer lugar, produce la existencia de unas bajas tasas de interés real lo que supone un poderoso incentivo para la fuga de capitales. Finalmente, lleva también a que una parte importante del ahorro se destine a financiar el presupuesto del Estado - a través de, entre otros mecanismos, un aumento de los impuestos- lo que ejerce un efecto pernicioso, desincentivador, sobre la producción, por el desaprovechamiento de recursos - para otros tipos de inversión- que significa 18 .

La conclusión que extraen es la de reducir el consumo (el FMI habla de "consumo excesivo"19, de "volumen excesivo de subvenciones al consumo"20, o más claramente de como "un país que está apremiado con dificultades de balanza de pagos y que no puede obtener más créditos en el exterior no tiene elección: debe reducir su consumo interior y sus importaciones"21). Es decir, según el FMI, el consumo debe ser reducido, por ser considerado excesivo... jen países donde la mayoría de la población se encuentra con probiemas de nutrición, de miseria, etcétera! En consonancia con todo esto se aplican esos llamados planes de ajuste es- 
tructural22 rigurosos para controlar los desequilibrios (o por mejor decir, algunos desequilibrios; nunca, por ejemplo, los que afectan a la tan desequilibrada distribución del ingreso) que implican una fuerte recesión, pero que permiten pagar deuda. $Y$ este sí es, efectivamente, el verdadero objetivo de estos planes: la transferencia de recursos de los países subdesarrollados a los desarrollados que, dada su concreción en un sistema regido por la lógica capitalista, toma la forma de transferencia de la clase desposeída de los países subdesarrollados a la capitalista de los países desarrollados - hegemonizada por la vinculada al capital bancario transnacional de marcada orientación especulativa-.

Así, los países subdesarrollados detraen una parte importante de sus escasos recursos en el pago de una deuda que es, por lo menos, discutible23. De este modo, el pago del servicio de la deuda -intereses y amortizaciones - alcanza elevadas proporciones tanto del total de ingresos por exportaciones de estos países como de su producto. Estos recursos se detraen fundamentalmente de los gastos sociales y productivos en los países latinoamericanos.

Todo ello se inserta en la dinámica transnacionalizadora de la economía mundial que les lleva a la destrucción de fuerzas productivas - desempleo, desindustrialización...-, a la transferencia neta de recursos al exterior -deterioro de los términos de intercambio, pago del servicio de la deuda-, a la desnacionalización de una porción de la base productiva a través de privatizaciones "salvajes", desregulación de la inversión exterior, políticas de capitalización de la deuda-, a la atracción indiscriminada e irrestricta de capital extranjero - parte importante del cual es de carácter especulativo-, a la liberalización de los intercambios comerciales -reduciendo todo tipo de proteccionismo, política en la que no se puede hablar de reciprocidad de los países desarrollados en los que éste, tanto en el plano arancelario como en el no arancelario, aumenta de forma sustancial- y, en general y derivado de todo ello, al empeoramiento de las condiciones de vida de la mayoría de la población. Dicha dinámica transnacionalizadora es la plasmación actual del carácter imperialista de la fase de desarrollo capitalista en que vivimos.

Por lo tanto, resumiendo, a lo que se asiste es a intentos de recuperación de la tasa de ganancia a escala mundial. Dentro de estos, la transferencia de recursos desde las FSCS desempeñan un importante papel. Transferencia de recursos que tiene lugar a través de dos modalidades: de un lado, mediante el aumento de la "sobreexplotación" a la clase dominada de estas formaciones sociales; de otro lado, a través de una reducción de la participación de la clase dominante de estos países en la plusvalía extraída allí mismo - es decir, la parte de plusvalía apropiada 
por el exterior respecto de la plusvalía total aumenta en términos proporcionales, lo cual tiene importantes efectos en la estructura social de estas formaciones sociales-. Y hay que señalar que todos los elementos financieros, comerciales, especulativos, etcétera, de los que hablábamos, son, precisamente, los mecanismos o instrumentos a través de los cuales se produce esa transformación en la apropiación del excedente. Por ello, una de las políticas centrales exigidas por el FMI para la renegociación de la deuda externa, es la apertura externa que supone un elemento central para una transnacionalización aún mayor (recordemos el carácter históricamente extravertido de estos países) que permita esa profundización en la modalidad tradicional de apropiación del excedente. Este es el significado profundo de estos procesos y de ahí su impacto para las FSCS.

\section{Recopilación}

1. Todo el período que se extiende a lo largo del siglo XX conforma la fase imperialista del desarrollo capitalista. Supone la consolidación de una sola economía mundial a la que todos los países están, de una u otra manera, vinculados. Expresados de forma muy sintética y simplificada, sus principales rasgos, mutuamente interrelacionados, son: aceleración de la concentración y centralización del capital, agudización de la tendencia al monopolio - con preponderancia del capital financiero-, predominio de la exportación de capitales sobre la de productos - con cierta autonomía de los circuitos financieros respecto de los de producción de mercancías-, presencia creciente de circuitos de capital ficticio en los que el dinero produce dinero sin pasar por el ámbito de la producción, incremento del componente especulativo y acrecentamiento de la tendencia al desarrollo desigual de las distintas formaciones sociales - lo que profundiza la situación de subdesarrollo y dependencia de las FSCS-.

2. El modelo de acumulación posbélico cuya concreción institucional se fija en la Conferencia de Bretton Woods de 1944, consolidando la posición hegemónica de Estados Unidos, supone un período de crecimiento de 25 años en los que, en todo caso, los elementos de la crisis crónica y estructural permanecen latentes. Efectivamente, este crecimiento no se debe a la superación de las contradicciones del modo de producción capitalista, sino, como señala Gill (1983; 8), a "las condiciones excepcionales de la posguerra (destrucción de masas enormes de fuerzas productivas, sobreexplotación de la fuerza de trabajo, pillaje de los países subdesarrollados...) y los medios artificiales (expansión del crédito y del endeudamiento, relanzamiento de los gastos militares...)".

3. La quiebra de este modelo de acumulación -el estallido de la cri- 
sis- en el tránsito de la década de los 60 a los 70 , pone de relieve el grado de crisis estructural del propio sistema capitalista en cuanto a su reproducción en el tiempo, expresando la agudización de sus contradicciones, ciertamente no resueltas: la paradoja desarrollo/destrucción de fuerzas productivas, el problema de la realización, las condiciones de valorización del capital, etcétera, expresiones a su vez de la contradicción esencial sintetizada en la oposición capital-trabajo. En este sentido, esta crisis es la crisis de la fase imperialista del capitalismo, la crisis del capitalismo.

4. La inserción primario-exportadora de América Latina en la división internacional del trabajo, consolidada históricamente a partir de la expansión del modo de producción capitalista, tiende a profundizarse en esta etapa. Así, tanto la Primera Guerra Mundial como la crisis del 29 tienen efectos catastróficos para la región. Ante ello, empiezan a surgir nuevas propuestas para transformar dicha inserción. La más importante es la de "crecimiento hacia adentro" que plantea CEPAL, consistente, en esencia, en la industrialización por sustitución de importaciones, para la que el Estado debe jugar un papel muy activo. Se busca transformar la reproducción distorsionada del capitalismo dependiente en un desarrollo capitalista endógeno y autocentrado. Estas propuestas gozan de gran aceptación y sus recomendaciones de política son aplicadas en casi todos los países.

5. El fracaso de estas políticas se constata apenas un par de décadas después, por razones vinculadas a la estructura productiva y distributiva, así como a su integración en la economía mundial. En este momento, años setenta, condiciones muy favorables en los mercados financieros internacionales - por exceso de líquidez derivado del déficit comercial estadounidense- llevan a casi todos los gobiernos y empresarios de la región a contraer (irresponsablemente tanto del lado de los prestamistas como de los prestatarios) un endeudamiento exterior muy barato pero muy arriesgado - por estar fijado a tasas de interés variables-, que no es utilizado con fines productivos salvo en muy pequeña medida.

6. La explosión de la crisis de la deuda en los primeros años de la década de los 80 pone de relieve la fragilidad de esta "opción". Sin embargo, todo ello resulta funcional para el capital bancario mundial como para el capital especulativo nacional de cada país- que recibe una gran transferencia de ingresos. El mecanismo que se utiliza para realizar esa transferencia -es decir, esa modificación en la modalidad de apropiación del excedente generado en estos países- es la aplicación de durísimos planes de ajuste impuestos - a través de la condicionalidadpor el FMI. El resultado de todo lo expuesto es el persistente deterioro de 
las condiciones de vida de la mayoría de la población. Es decir, de nuevo, la reproducción del subdesarrollo. Y la concreción en términos de lógica en que se traduce viene caracterizada, de forma especial, por la dinámica transnacionalizadora de estos países que no es sino la plasmación actual del carácter imperialista de la fase de desarrollo capitalista en que vivimos.

\section{Referencias bibliográficas}

ARRIZABALO MONTORO, Xabier; Milagro o quimera: la economía chilena durante la dictadura, La Catarata, Madrid, 1995.

----- ; Significado estructural de las políticas del Fondo Monetario Internacional (FMI) en América Latina en la actualidad, Cuadernos de Africa-América Latina, $n^{\circ} 15$, Sodepaz, Madrid, 1994.

* CIZE, Pierre y otros; Le Fonds monétaire international (F.M.I.): une entreprise de pillage des peuples, SELIO, Paris, 1990.

DAUBERNY, Michel; Las consecuencias de la supervivencia del capitalismo: ¿"expansión ilimitada" o programa de regresión mundial?, La Verdad, número 3 (nueva serie), CIR, Madrid, diciembre 1991.

GILL, Louis; Économie mondiale et impérialisme, Boréal Express, Québec, 1983.

LENIN, V. I.; El imperialismo, fase superior del capitalismo, Fundamentos, Madrid, 1974.

MARX; Karl; El Capital (Crítica de la Economía Política), Siglo XXI, 8 vols., Madrid, 1984; primera edición de la traducción: Buenos aires, 1975.

PALAZUELOS, Enrique (ed.); Dinámica capitalista y crisis actual, Akal, Madrid, 1988.

TRIBUNAL INTERNACIONAL CONTRA LA DEUDA; Sentencia, Graphos 100 Editores, Lima, 1989.

VALENZUELA F., José; Crítica del modelo neoliberal, Facultad de Economía, UNAM, México, 1991.

VUSKOVIC BRAVO, Pedro; La dualización de las sociedades latinoamericanas, mimeo, junio 1991.

\section{Notas}

1. El presente artículo se basa en el capítulo IV de ARRIZABALO, Xabier; Transnacinalización y subdesarrollo: Chile, 1973/1990 (Resultados económicos y significado histórico de la dictadura y el neoliberalismo), Tesis Doctoral, Madrid, 1993.

2. Profesor de Economía de la Universidad Complutense de Madrid:

3. Resulta oportuno hacer patente que plantear la periodización y parcelación espacial expuestas, obedece a razones de claridad expositiva. La realidad no presenta rupturas tajantes sino que existe una fuerte interrelación tanto entre las distintas fases históricas como entre las diversas áreas geográficas.

4. Esta formulación del fenómeno del imperialismo es una de las más clásicas. Existen, obviamente, muchos otros autores que han abordado el tema. Cita- 
mos ésta porque entendemos que constituye una buena síntesis. No obstante, para abundar en el tema se pueden consultar textos de otros autores tales como Hobson, Hilferding, Luxemburgo, Wolff, Bujarin, Preobrazhensky, Baran y Sweezy, etcétera. También pueden verse algunos de otros autores como Amin, Palloix o Emmanuel, que tratan temáticas afines.

5. En relación a este punto, es oportuno comentar que la traducción más adecuada del título original del texto de Lenin citado anteriormente no dice "fase superior" sino "fase suprema". Y, obviamente, la diferencia entre la utilización del comparativo y la del superlativo es crucial.

6. Respecto al uso del término "nuevo" corresponde efectuar una aclaración. Hacemos nuestra la explicación de PALAZUELOS (1986; pág. 69), cuando comenta que "lógicamente, en un sentido estrictamente literal dicho uso no sería acertado (...) sin embargo, lo que sí resulta nuevo - y este es el sentido aquí utilizado- es la relación orgánica de todos esos elementos, es decir su configuración y articulación en este modelo de acumulación".

7. Véase PALAZUELOS (1986; págs. 64 y siguientes).

8. A los efectos de lo que nos ocupa en este momento, tratamos la tasa de ganancia en términos monetarios, a partir de la traslación de valores a precios, por la importancia creciente que tiene dicha traslación como consecuencia de las tendencias inflacionarias y del problema de la realización.

9. Esta afirmación no implica la idea de que este área sí sea, más o menos, homogénea. Nada más lejos de la realidad. No obstante, las tendencias históricas recientes — de las que nos ocupamos - sí presentan elementos comunes para la mayoría de los países de América Latina. Los rasgos peculiares de cada formación social - las cuales, por cierto, tampoco son homogéneasno son abordados aquí.

10. Esto es significativo no ya de la posibilidad de éxito de esta propuesta, sino de como, simplemente la factibilidad de intentarlo está supeditada y subordinada a la coyuntura de los países desarrollados. De modo que si se permite la aplicación este tipo de políticas es bien porque no afecta sustancialmente a los intereses del capital monopólico por la coyuntura expansiva, o bien porque incluso les resulta funcional el trasvase de ciertas industrias cuya base tecnológica es más o menos obsoleta y cuyos costes de trabajo siguen suponiendo una alta participación relativa, que hace rentabilizar dicho trasvase por el menor nivel salarial, en términos relativos, en estos países.

11. Esta crítica también es aplicable para las propuestas actuales que sitúan al progreso técnico como la "panacea" que resuelva el problema del subdesarrollo. Efectivamente, el progreso técnico es crucial por su vinculación con la productividad ( $\mathrm{y}$ de ésta, a su vez, con la competitividad, etcétera), pero parece obviarse que el progreso técnico se halla igualmente sometido a la lógica capitalista - que actúa a escala mundial- lo que condiciona la posibilidad de su utilización transformadora en dirección contraria a los intereses de dicha lógica. Y el subdesarrollo - si se quiere, el mantenimiento de una mayoría de la población en unas condiciones que le impiden la satisfacción de sus necesidades básicas - forma parte de los intereses, de las necesidades, de la mencionada lógica.

12. En los países del área exportadores de petróleo, entre los que destacan Méxi- 
co y Venezuela, la situación "irreal" aludida - en cuanto a su desvinculación de la base productiva - se da en mucha mayor medida por el enorme incremento de divisas recibidas, consecuencia del alza en los precios internacionales de este recurso energético.

13. A diferencia del período inmediato a la posguerra, en que la mayor parte de los créditos eran suministrados por organismos multinacionales con tasas de interés fijas, en esta fase, la mayoría, proceden de la banca privada comercial y están contraídos a tasas de interés variable (generalmente tomando como referencia las de mercado - "LIBOR" o "Prime Rate" - a las que se le añade un margen).

14. Discurso de Jacques de Larosière, antiguo Director General del FMI, reproducido en el Boletín del FMI, 14/6/82. Tomado de GLUCKSTEIN (1990; pág. 36). La traducción es nuestra -XAM- La versión original dice textualmente: "est subordonnée à l'adoption par les pays emprunteurs de mesures correctives". El uso de la negrita es de los autores.

15. Boletín del FMI, 15/3/1982, tomado de GLUCKSTEIN (1990; pág. 36). La traducción es nuestra -XAM- La versión original dice textualmente: "La conditionnalité se rapporte à l'obligation, impossée par le Fonds aux pays membres qui désirent recourir à ses ressources, dadopter des politiques d'ajustement économique (...). Le lien entre le financement et l'ajustement es au centre de la conditionnalité". El uso de la negrita es de los autores.

16. Si se inspiran en el enfoque neoliberal es por su funcionalidad a las necesidades del capital en el momento actual (de la misma manera que, en otros momentos históricos, el referente había sido, por ejemplo, keynesiano). Más allá de las contradicciones en su aplicación, asunto éste que aparece en todos los casos.

17. Una visión que incluyera las recomendaciones de política del FMI para los países desarrollados, permitiría una mejor perspectiva respecto del significado de la situación actual de la economía mundial. Lamentablemente, excede al alcance de este trabajo, si bien es oportuno citar su dimensión impulsora del desmantelamiento de todo lo que había llegado a conformarse como "Estado del Bienestar" (a través de los siguientes mecanismos: la preeminencia absoluta del objetivo de estabilidad de precios - fundamentalmente control de la inflación- sobre los de crecimiento del producto o de redistribución del ingreso; las políticas de privatización; la reorientación de la intervención del Estado, etcétera), siendo digno de recalcar como se otorga una marcada prioridad a los aspectos financieros sobre los productivos.

18. La refutación de este tipo de razonamiento pasa por observar el precio que suponen el control de la inflación - sobre los otros objetivos de política-, la afluencia de capitales meramente especulativos - por el alza de los tipos de interés real-, la reducción de la intervención del Estado -mediante, por ejemplo y de forma señalada, la disminución de gastos sociales- y, más gravemente, la reducción del consumo. $O$, yendo más allá, el significado último de la aplicación de estos planes, esto es, la transferencia neta de cantidades ingentes de recursos de los países subdesarrollados que puedan coadyuvar a la pretensión de recuperar la tasa de ganancia. Transferencia cuyo efecto inmediato es el empeoramiento de las condiciones de vida de la 
mayor parte de la población de estas sociedades. En todo caso, la refutación de todo ello se llevará a cabo de forma particularizada para los distintos casos.

19. Discurso de Jacques de Larosière, 6/9/82, reproducido en el Boletín del FMI, 27/9/82. Tomado de GLUCKSTEIN (1990; pág. 44). La traducción es nuestra -XAM-. Versión original: "consommation excessive".

20. Discurso de Jacques de Larosière, 8/6/82, reproducido en el Boletín del FMI, 20/6/82. Tomado de GLUCKSTEIN (1990; pág. 44). La traducción es nuestra -XAM-. Versión original: "volume excessif de subventions à la consommation".

21. Discurso de Jacques de Larosière, reproducido en el Boletín del FMI, 17/10/ 83. Tomado de GLUCKSTEIN (1990; pág. 45). La traducción es nuestra -XAM-. La versión original dice textualmente: "Un pays qui est aux prises avec des difficultés de balance des paiements et qui ne peut plus obtenir de crédits à l'exterieur nà pas le choix: il doit réduire sa consommation intérieure et ses importations".

22. Estos planes consisten, en esencia, en "recomendaciones" para la consecución de economías de "libre" mercado y plenamente abiertas al exterior. Para ello se arbitran una serie de reformas: liberalización de los mercados (de bienes - mediante la eliminación de controles de precios-, de dinero - a través de la desregulación financiera-y de trabajo - con la anulación de conquistas históricas de los trabajadores-; apertura al exterior (tanto en el terreno comercial con la reducción e igualación de los aranceles, como en el financiero con la libertad de movimientos internacionales de capital) y, reducción del papel del Estado (disminución del sector público, privatización de empresas públicas, etcétera).

23. No es este el espacio para discutir la legitimidad de la deuda. Además, los distintos casos varían entre sí considerablemente. No obstante, sí se pueden citar algunos ejemplos de deuda manifiestamente ilegítima como aquella contraída por las dictaduras conosureñas empleada en la represión de sus propias poblaciones, o en proyectos bélicos, o aquella que casi inmediatamente "volaba" a cuentas corrientes en bancos extranjeros. En todo caso, la idea de la corresponsabilidad entre prestamistas y prestatarios en el problema del endeudamiento constituye una cuestión de mínimos. 